\title{
Lyapunov Function and Sliding Mode Control Approach for Solar-PV Grid Interface System
}

\author{
M.Rezkallah, Member, IEEE, S.Sharma, Senior Member, IEEE, A.Chandra, Fellow Member, IEEE \\ B.Singh, Fellow Member, IEEE, and D.R. Rousse
}

\begin{abstract}
This paper deals with control of a solar photovoltaic (PV) power generating system interfaced with the grid. A sliding mode control approach (SMC) is used for achieving maximum power tracking (MPT) control of solar-PV array. The Lyapunov function-based control approach is designed and modeled for the DC-AC inverter to serve the functions of an active power injection to the grid, balanced grid currents at unity power factor and load currents harmonics compensation. Proposed approaches eliminate the need of adjustment of system parameters under changing loads and generation scenario. The effectiveness of proposed control strategies is established using its stability analyses. The performance of solar-PV power generating system with proposed control algorithms is demonstrated using simulation and experimental studies under various operating conditions.
\end{abstract}

Index Terms - Lyapunov-based function, MPT, PV array, power quality improvement sliding mode control approach, stability analysis.

\section{INTRODUCTION}

$\mathrm{R}$ ENEWABLE energy programs are receiving reasonable attention worldwide to cater the needs of electricity. According to U.S. Energy Information Administration (EIA) reports, the growth rate of such programs is $2.5 \%$ per/year [1]. In fact, there is tremendous potential available to produce electricity using the solar energy. The recent trends are indicating increase in capital investments of solar based power projects. Solar photovoltaic (PV) panel generates DC power and hence additional components, such as power converters are instrumental to tie it with the AC grid. Further, solar based power generation is intermittent in nature which varies very rapidly changes in solar irradiation. Therefore, solar based power penetration into grid adversely affects the stability of the network and quality of supply. For the secure and reliable integrations of such solar-PV systems with the grid, different standards are in practice in various countries such as in [2]. To control the operation under these guidelines, solutions have also been reported in the literature using a single-stage inverter [3-4] and two-stage inverter [5-8].

To know which topology is preferred for a typical application, a comparative study has been made in [9]. The single stage topology is considered more efficient due to less number of components. However, two-stage power conversion provides more flexibility in design, operation and control. The DC-DC converter is employed in between solar-PV array and DC link of an inverter and controlled to achieve maximum power tracking (MPT) from a solar PV array.

Various control approaches have been reported in the literature to improve the efficiency of solar PV array [10]. Each MPT method has its own advantages and disadvantages. Compared to the existing MPT methods, perturbation and observation is widely used in industry due to its simplicity, but it suffers during rapid solar irradiation change [10-11]. In addition, at steady state, the operating point oscillates around the maximum power point (MPP), which leads in losing some amount of the available energy, increased switching noise and losses. Many solutions have been reported in the literature to solve this problem. In [12], it has been proposed to reduce steps size. This technique is effective but it makes the control sluggish during rapid change in solar irradiation. In [13], adaptive perturbation step size has been employed to get better performance. However, this method is complex in implementation as it needs the location of the operating point. In addition, the control is switched in between adaptive duty cycle and fixed duty cycle control, which makes its implementation difficult in real time.

Sliding mode approach (SMC) as solution is proposed in [14] to solve the problem related to the operating point that oscillates

Manuscript received October 26, 2015; revised February 17, 2016 and May 4, 2016; accepted June 14, 2016. This work was supported in part by the Fonds de Recherche du Québec - Nature et Technologies (FRQNT).

M. Rezkallah and A. Chandra are with the Electrical Engineering Department, École de Technologie Supérieure, 1100 Notre-Dame Montréal, Québec H3C1K3 Canada (miloud.rezkallah.1@ ens.etsmtl.ca, ambrish.chandra@etsmtl.ca).

S. Sharma is with the Electrical Engineering Department, Shri G. S. Institute of Technology \& Science, 23, Park Road, Indore-452003, India. (ssharma @sgsits.ac.in).

B.Singh is with the Electrical Engineering Department, Indian Institute of Technology Delhi, New Delhi-110016, India. (bsingh@ee.iitd.ac.in).

D.R. Rousse is with Mechanical Engineering Department, École de Technologie Supérieure, 1100 Notre-Dame Montréal, Québec H3C1K3 Canada.(daniel.rousse@etsmtl.ca).

(C) 2016 IEEE. Personal use of this material is permitted. Permission from IEEE must be obtained for all other uses, in any current or future media, including reprinting/republishing this material for advertising or promotional purposes, creating new collective works, for resale or redistribution to servers or lists, or reuse of any copyrighted component of this work in other works. The final publication is available at http://dx.doi.org/10.1109/tie.2016.2607162 
around the MPP, and to ensure stability of system with fast dynamic response. However, chattering phenomenon is its major drawback and because of it, this induces many undesirable oscillations in control signal. Therefore, to maintain the amplitude of oscillation at low level, chattering must be decreased or eliminated. To achieve this objective, many chattering suppression methods have been suggested in the literature. In [15, 16], boundary layer solution is proposed, and in [17], observer-based solution is used. Furthermore, in [18], sliding mode is limited to an inner control loop of a cascaded control structure to reduce the chattering, and in [19-23], generating integral sliding mode, terminal sliding mode control (TSMC) and non-singular terminal sliding mode control (NTSMC) have been proposed.

Each proposed technique has its own advantages and disadvantages, but it is clear that the selection criterion of solution, which is able to eliminate the chattering phenomenon, is related to the order of the mathematical model of the uncertain system and the type of application. Nevertheless, in some applications, such as aircraft and electric automotive control, which require a high level of precision, advanced SMC is strongly advocated. Unfortunately, their implementations in real time are challenging. However, in other typical applications, SMC is applied to the control of the DC-DC converters or DC-AC inverters. In such applications, a conventional nonlinear SMC is considered more suitable as they are less complex and easy to implement in real time [24].

Improved nonlinear SMC to drive the PV voltage to follow its reference is proposed in [25]. This approach is simple, but unfortunately the use of the low pass-filter between the Perturb and Observe (P\&O) controller and the SMC influences the dynamic response of the system. Further, the use of sensed capacitor current in the model reduces the reliability particularly in high environmental temperature conditions.

For improving the grid stability and power quality at the point of common coupling (PCC) and delivering the generated power from the PV array in to the grid, DC-AC inverter is mostly employed. Several control schemes have been reported in the literature to achieve above tasks using DC-AC inverter, such as model predictive control and instantaneous power quality (PQ) control [26]. Some control approaches have used adaptive algorithms such as presented in [27, 28]. However, most of these approaches have not extensively verified under the presence of nonlinear loads with grid supply. In addition, they have employed more number of proportional-integral (PI) controllers, due to which steady-state error at the fundamental frequency cannot nullified in presence of dynamics of the integral action.

Lyapunov function based control for shunt hybrid active filter is proposed in [29] to improve the power quality at the PCC. Compared to the other control approaches, the Lyapunov function based control is robust and effective because of the use of less PI controllers and stability enhancement. Unfortunately, authors have not considered all system parameters in selection of the gain controller, which leads that the proposed approach may suffer during transition period. To overcome this drawback, the authors in [30], have enhanced this control approach by integrating new outer voltage loop in order to eliminate the steady-state error in the output voltage during perturbation or transition period. This approach is effective but it cannot be used for three phase inverter.

Inspired from the above work, this paper presents sliding mode based layer concept and Lyapunov function approach used for the control of DC-DC boost converter and the DC-AC inverter, respectively. The proposed approach eliminates the application of many PI controllers for the control and uses only single PI controller for DC link voltage regulation. The detail modeling, design of the gain controllers and stability analysis of proposed approach are investigated to prove its efficacy under various field operating conditions. Simulation and experimental results are presented subsequently in the presence of different loads and change in solar irradiations.

\section{SYSTEM CONFIGURATION}

Fig. 1 shows the proposed system under study. It consists of solar-PV array tied to the grid through a DC-DC boost converter and a three-phase DC-AC inverter. To attenuate the switching ripples at the AC terminals of the DC-AC inverter, a starconnected three terminal RC ripple filter is connected. The DC-DC boost converter is controlled using SMC approach in order to achieve MPT from PV array with regulating the DC link voltage of PV array. The DC-AC inverter is controlled using Lyapunovfunction based approach in order to feed the solar-PV generated power to the grid, to compensate harmonics present in load currents and to ensure balanced grid currents at unity power factor.

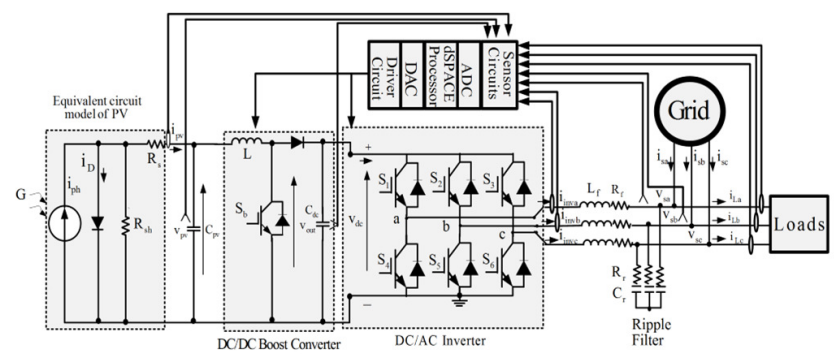

Fig. 1. Schematic diagram of solar-PV power generation system. 


\section{MODELING AND CONTROL OF CONVERTERS}

Modeling, control and stability analysis of the DC-DC boost converter and the DC-AC inverter are presented as follows.

\section{A. Modeling and Design of Control Scheme for DC-DC Boost Converter}

The objectives of the proposed control for the DC-DC boost converter are to achieve the MPT from the solar PV array and step up its output voltage. To achieve these tasks, the PV output current $\left(i_{p v}\right)$ and voltage $\left(v_{p v}\right)$, as well as the output voltage of the boost converter $\left(v_{\text {out }}\right)$, which represents the DC bus voltage $\left(v_{d c}\right)$ are sensed. The control provides the duty cycle $(u)$ required for switching the control switch.

The model of boost converter is obtained based on two operating modes in continuous conduction as;

For $S_{b}=1(O N)$

$$
\begin{aligned}
& L\left(\partial i_{L} / \partial t\right)=v_{p v} \\
& C_{d c}\left(\partial v_{d c} / \partial t\right)=-\left(v_{d c} / R\right)
\end{aligned}
$$

For $S_{b}=0(\mathrm{OFF})$,

$$
\begin{aligned}
& L\left(\partial i_{L} / \partial t\right)=v_{p v}-v_{d c} \\
& C_{o u t}\left(\partial v_{d c} / \partial t\right)=i_{L}-\left(v_{d c} / R\right)
\end{aligned}
$$

where $L, C_{\text {out }}$ and $R$ represent inductance, capacitance of the filter and the equivalent load resistance for the boost converter, respectively.

Based on (1) to (4), the state-space average model of DC-DC boost converter are obtained as,

$$
\begin{aligned}
& \left(\partial i_{L} / \partial t\right)=\left(v_{p v} / L\right)-(1-u)\left(v_{d c} / L\right) \\
& \left(\partial v_{d c} / \partial t\right)=\left(1 / C_{\text {out }}\right)\left[\left(i_{L}(1-u)\right)-\left(v_{d c} / R\right)\right]
\end{aligned}
$$

where $u$ is the duty cycle.

\section{B.MPT Control Based on Sliding Mode Approach}

The MPT is achieved using the SMC. Fig. 2 shows the block diagram of proposed SMC based control of DC-DC converter. The design is obtained using the following steps.

\section{1) Selecting of Sliding Surface}

The sliding surface $\sigma$ is selected as given in (7), to ensure reaching the surface and extracting the maximum power from the solar PV array,

$$
\sigma=\left(\partial P_{p v} / \partial i_{p v}\right)=0
$$

where $P_{p v}$ is the PV output power, which is defined as,

$$
P_{p v}=v_{p v} i_{p v}
$$

Substituting (8) in (7), the following expression is obtained as,

$$
\sigma=\left(\partial P_{p v} / \partial i_{p v}\right)=\partial\left(v_{p v} i_{p v}\right) / \partial i_{p v}
$$

Rearranging (9), the sliding surface is defined as,

$$
\sigma=v_{p v}+i_{p v}\left(\partial v_{p v} / \partial i_{p v}\right)
$$




\section{2) Equivalent Criteria for Control}

The equivalent control is obtained by setting the derivative of (10) to 0 . So, the structure of the desired control is defined as,

$$
u=u_{e q}+k \operatorname{sign}(\sigma)
$$

where $k$ is a gain constant and $u_{e q}$ is the equivalent control, which is obtained as,

$$
\begin{aligned}
(\partial \sigma / \partial t) & =\left(\partial \sigma / \partial i_{L}\right)\left(\partial i_{L} / \partial t\right) \\
& =\left(\partial \sigma / \partial i_{L}\right)\left[\left(v_{p v} / L\right)-(1-u)\left(v_{d c} / L\right)\right]
\end{aligned}
$$

The non-trivial solution of (12) is given as,

$$
v_{p v}-(1-u) v_{d c}=0
$$

From (13), the following equivalent control is obtained,

$$
u_{e q}=1-\left(v_{p v} / v_{d c}\right)
$$

The duty cycle $u$ is limited between ( 0 and 1$)$. Therefore, the structure of SMC is defined as;

$$
u=\left\{\begin{array}{l}
1 \text { if } u_{e q}+k \operatorname{sign}(\sigma) \geq 0 \\
0 \text { if } \quad u_{e q}+k \operatorname{sign}(\sigma) \leq 0
\end{array}\right.
$$

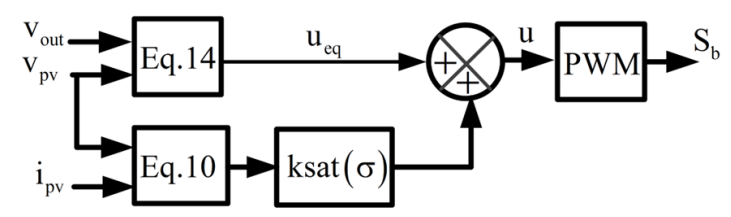

Fig. 2. Scheme for Control of the DC-DC Boost converter.

\section{3) Stability Analysis}

The objective of approach using SMC is to ensure the convergence of the operating points to define the sliding boundary. Therefore, for assuring the stability of the control, Lyapunov function is used as,

$$
V=(1 / 2) \sigma^{2}
$$

The system is considered globally stable if the derivative of (16) is negative.

$$
(\partial V / \partial t)=\sigma(\partial \sigma / \partial t)<0
$$

Substituting (5) and (10) in (17), the following relationship, which is composed of three terms, is obtained,

$$
\begin{aligned}
& \overbrace{\left(v_{p v}+i_{L}\left(\partial v_{p v} / \partial i_{L}\right)\right.}^{\text {Term1 }}) \\
& \overbrace{\left(\left(v_{p v} / L\right)-(1-u)\left(v_{d c} / L\right)\right)}^{\text {Term } 3}<0
\end{aligned}
$$

where, $v_{p v}$ is the PV output voltage, and it is defined as [19],

$$
v_{p v}=\left(k_{b} T A / q\right) \ln \left(\left(i_{p h}+i_{D}-i_{L}\right) / i_{D}\right)
$$


The PV saturation current $\left(i_{D}\right)$ and the light-generated current $\left(i_{p h}\right)$ are expressed as,

$$
\begin{aligned}
& i_{D}=i_{r r}\left(T / T_{r}\right)^{3} \operatorname{EXP}\left[\left(\left(q E_{g}\right) /(K Q A)\right)\left(\left(1 / T_{r}\right)-(1 / T)\right)\right](20) \\
& i_{p h}=G\left[i_{s c r}+k_{i}\left(T-T_{r}\right)\right]
\end{aligned}
$$

where $k_{b}, T, A, q, G, i_{s c r}, T_{r}, k_{i}, i_{r r}, E_{g}$, and $Q$ represent the Boltzmann's constant, cell temperature, ideality factor, charge of an electron, solar irradiance, short-circuit current, reference temperature, short-circuit temperature coefficient, saturation current, band-gap energy of the material and total electron charge respectively.

The terms in (18) contain the derivative and the second derivative of (19), which are given as,

$$
\begin{gathered}
\left(\partial v_{p v} / \partial i_{L}\right)=-\overbrace{\left(k_{b} T A / q\right)}^{\text {Term } 1} \overbrace{\left(i_{D} /\left(i_{p h}+i_{D}-i_{L}\right)\right.}^{\text {Term 2 }}) \\
\left(\partial^{2} v_{p v} / \partial^{2} i_{L}\right)=-\overbrace{\left(k_{b} T A / q\right)}^{\text {Term } 1} \overbrace{\left(i_{D} /\left(i_{p h}+i_{D}-i_{L}\right)^{2}\right)}^{\text {Term } 2}-\bar{c}
\end{gathered}
$$

In order to verify that the system is globally stable, the sign of the (18) is obtained. It is observed that (18) contains three terms. The first and the second terms contain the first derivative and the second derivative of the output PV voltage given in (22) and (23) respectively. However, to obtain the sign of (18), it's better to verify the sign of each term in this expression independently. With help of the parameters of the PV array given in Table II in Appendix [19], the first term of (22) is calculated equal to $\left(k_{b} T A / q=0.0026\right)$. In addition, as it is observed in equivalent model of PV array shown in Fig. 1 that the current $i_{p h}$ is always greater than currents $i_{D}$ and $i_{L}$. Therefore, the second term in (22) is always less than the first one. Based on above, the sign of (22) is always negative.

The same logic is applied to determine the sign of the second derivative of the output voltage given in (23). In comparison with the (22), the denominator of the second term in (23) is square, it leads that second term is smaller than the first term $\left(k_{b} T A / q=0.0026\right)$. Therefore the sign of (23) is also negative. Based on these results it is concluded that the sign of the second term of (18) is negative.

The sign of the first term in (18) is positive because of the value of the output PV voltage is positive and greater to $\left(i_{L}\left(\partial v_{p v} / \partial_{i L}\right)\right)$. Further, the sign of the third term in (18) must be positive. To verify the sign of third term in (18), one replaces $d$ in the third termby (11) and (14). After rearranging and simplifying the third term, following expression is obtained as,

$$
(\overbrace{\left(v_{d c} / L\right)}^{\text {Term } 1} \overbrace{k \operatorname{sgn}(\sigma)}^{\text {Term } 2})>0
$$

The first term is always positive. Therefore, to satisfy the condition given in (18), the second term in (24) should be positive, which is obtained by applying the following conditions,

$$
\begin{cases}\text { if } \operatorname{sign}(\sigma)<0, & k<-1 \\ \text { if } \operatorname{sign}(\sigma)>0, & k>1\end{cases}
$$

where $k$ is positive gain parameter.

Based on the above discussion, it is verified that proposed control approach is stable for DC-DC boost converter.

The chattering phenomenon caused by the continuous jumping of the system trajectory when it is operating near sliding surface $(\sigma=0)$, is the major drawbacks of the proposed SMC approach given in (15). Therefore, to eliminate this undesired chattering phenomenon, sliding layer concept is used as shown in Fig.2 and described below:

$$
\operatorname{sat}(\sigma, \Phi)\left\{\begin{array}{cc}
1 & \sigma \succ \Phi \\
\sigma / \Phi & |\sigma| \leq \Phi \\
-1 & \sigma \prec-\Phi
\end{array}\right.
$$


Or

$$
\operatorname{sat}(\sigma, \Phi)= \begin{cases}\operatorname{sign}(\sigma) & |\sigma| \succ \Phi \\ \sigma / \Phi & |\sigma| \leq \Phi\end{cases}
$$

where $\Phi$ represents the sliding layer, which is defined between -0.5 and 0.5 .

\section{4) Controller Gain Design}

To ensure that the proposed SMC performs better, the control gain $(k)$ should be selected to drive the trajectory to the slide surface in infinite time. The dynamic response of the inductor current, which represents the output PV current for different values of ' $k$ ' is shown in Fig.3. It is observed that for high values of $k$, the dynamic response of the inductor current is faster. Therefore, for fast dynamic response, the control gain is selected equal to $(k=50)$.

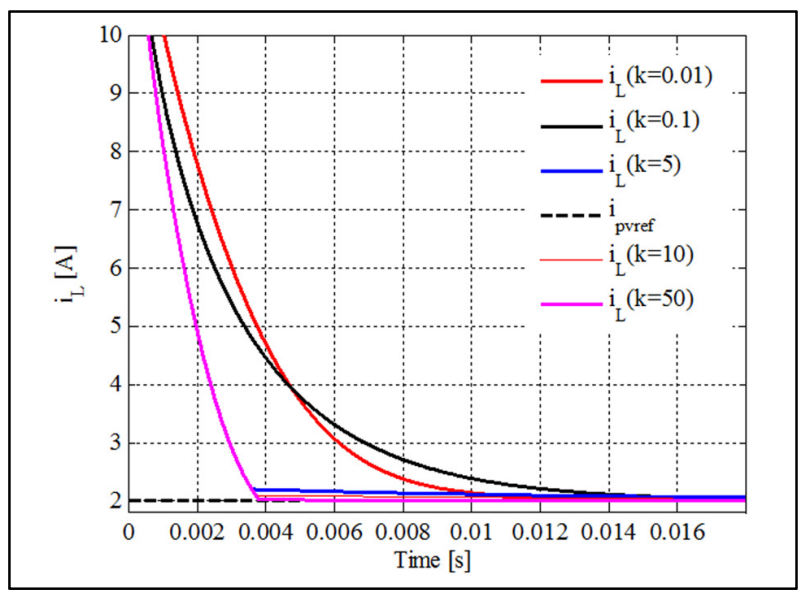

Fig. 3. Dynamic response of inductor current for different gain control values. 


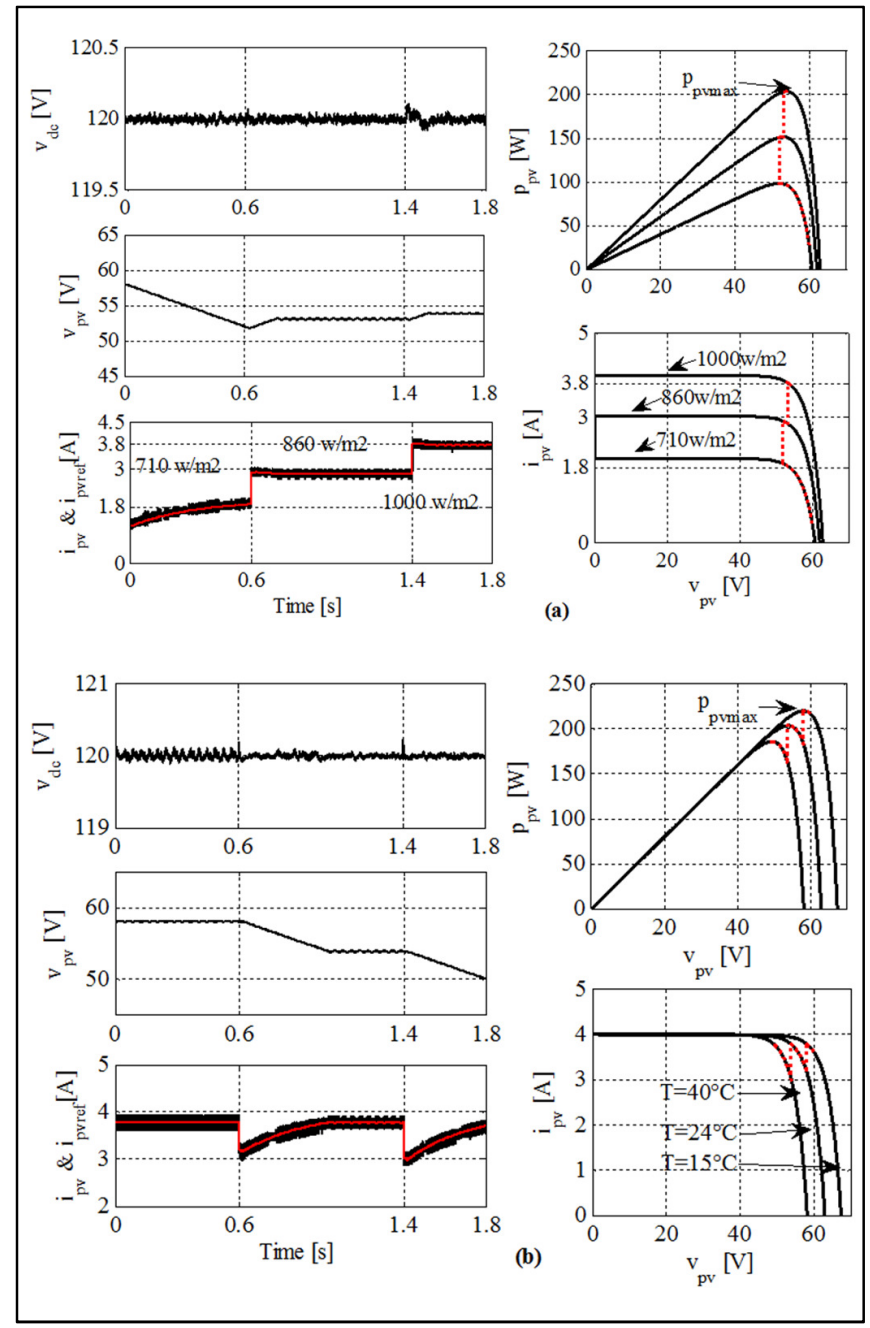

Fig. 4. Simulation results of the $D C$ link voltage $\left(v_{d c}\right)$, output $P V$ voltage and current, $i_{p v}=f\left(v_{p v}\right)$ and $p_{p v}=f\left(v_{p v}\right)$ at: $\left.a\right)$ fixed temperature and different solar irradiation, and b) at fixed solar irradiation and different temperature.

To test the performance of the proposed SMC using the optimal value of $k$ are shown in Fig.4. The simulations are carried out using Matlab/Simulink. Observations are obtained at fixed temperature $\left(\mathrm{T}=24^{\circ} \mathrm{C}\right)$ and different solar irradiations as shown in Fig. 4(a), and at different temperatures with fixed solar irradiations $\left(\mathrm{G}=1000 \mathrm{w} / \mathrm{m}^{2}\right)$, as shown in Fig.4 (b). The output PV current $\left(i_{p v=i L}\right)$ follows its desired reference at finite time and the output PV voltage $\left(v_{d c}=v_{o u t}\right)$ is maintained constant during both tests, which confirm that the proposed SMC performs better at this optimal value of control gain.

\section{C.MPT Control Based on Sliding Mode Approach}

The block diagram of proposed Lyapunov based control algorithm for DC-AC inverter is shown in Fig. 5. The inverter is switched to control the active power flow between the DC

bus and the grid, to improve the power quality at the PCC by compensating load current harmonics and to balance the grid currents at unity power factor. For the control scheme, load currents, inverter currents and grid voltages are sensed.

The control laws $u_{n a}, u_{n b}$ and $u_{n c}$ are determined using these sensed signals. The Park's transformation is used to obtain synchronously rotating d-q variables for load currents, inverter currents and grid voltages. The phase-locked loop (PLL) is used to calculate the grid voltage phase angle used for the transformation. The control laws are obtained using mathematical modeling of the DC-AC inverter, control design and after verification using stability analysis.

The mathematical expressions used for the modeling are as follows. Applying Kirchhoff laws at inverter AC and DC terminals provides expression for three-phase supply system, which are transferred into synchronous rotating grid voltage reference frame using Park's transformation. The resulting mathematical model in d-q reference frame is expressed as, 


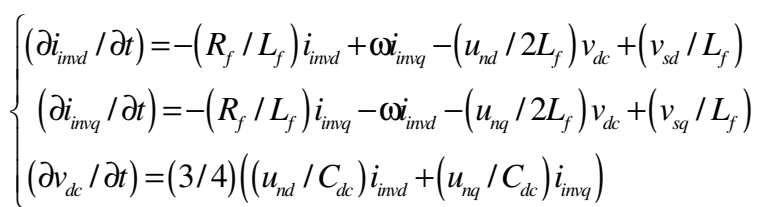

where $R_{f}, L_{f}, C_{d c}, i_{i n v d}, i_{i n v q}, v_{s}, v_{d c}, \omega, u_{n d}$ and $u_{n q}$ denote the equivalent resistance and inductance at the AC terminals of DC-AC inverter, DC link capacitor of the DC bus, inverter currents in d-q frame, equivalent voltage in $\mathrm{d}$ frame, DC voltage, angular frequency of the grid and the control laws in d-q reference frame, respectively.

For the unity power factor operation of grid currents, the reference q-axis component of grid currents $\left(i_{s q}\right)$ must be kept equal to zero. Moreover, the q-axis component of the grid voltage is considered equal to zero $\left(v_{s q}=0\right)$ for reference frame aligned with voltage vector. Therefore, under the steady-state conditions, following equality conditions are justified,

$v_{d c}=v_{d c r e f}, i_{s d}=I_{s m}, i_{s q}=0, u_{n d}=u_{n d 0}, u_{n q}=u_{n q 0}, i_{\text {invd }}=i_{\text {invdref }}=I_{s m}-i_{L d}, i_{\text {invq }}=i_{\text {invqref }}=-i_{L q}$

where $I_{s m}, i_{i n v d r e f}, i_{\text {invqref }}, u_{n d 0}$ and $u_{n q 0}$ denote the amplitude of the grid current, d-q axis inverter reference currents and the d-q axis steady-state value of the control variables.

Putting these equalities in (28), the following expressions are obtained as;

$$
\left\{\begin{array}{l}
u_{n d 0}=\left(2 / v_{d c r e f}\right)\left[v_{s d}+R_{f} i_{L d}+L_{f}\left(\partial i_{L d} / \partial t\right)-\omega L_{f} i_{L q}-R_{f} I_{s m}\right] \\
u_{n q 0}=\left(2 / v_{d c r e f}\right)\left[R_{f} i_{L q}+L_{f}\left(\partial i_{L q} / \partial t\right)+\omega L_{f}\left(I_{s m}-i_{L d}\right)\right]
\end{array}\right.
$$

And

$$
\left\{\begin{array}{l}
u_{n d}=u_{n d 0}+\Delta u_{n d} \\
u_{n q}=u_{n q 0}+\Delta u_{n q}
\end{array}\right.
$$

where $\Delta u_{n d}$ and $\Delta u_{n q}$ denote perturbations of global switching functions respectively.

\section{1) Stability Analysis}

The stability of the proposed control system is verified using Lyapunov stability criterion, which is presented in Section III $\left(B_{3}\right)$. The system under consideration is stable if the total energy of the DC-AC inverter system decreases along the

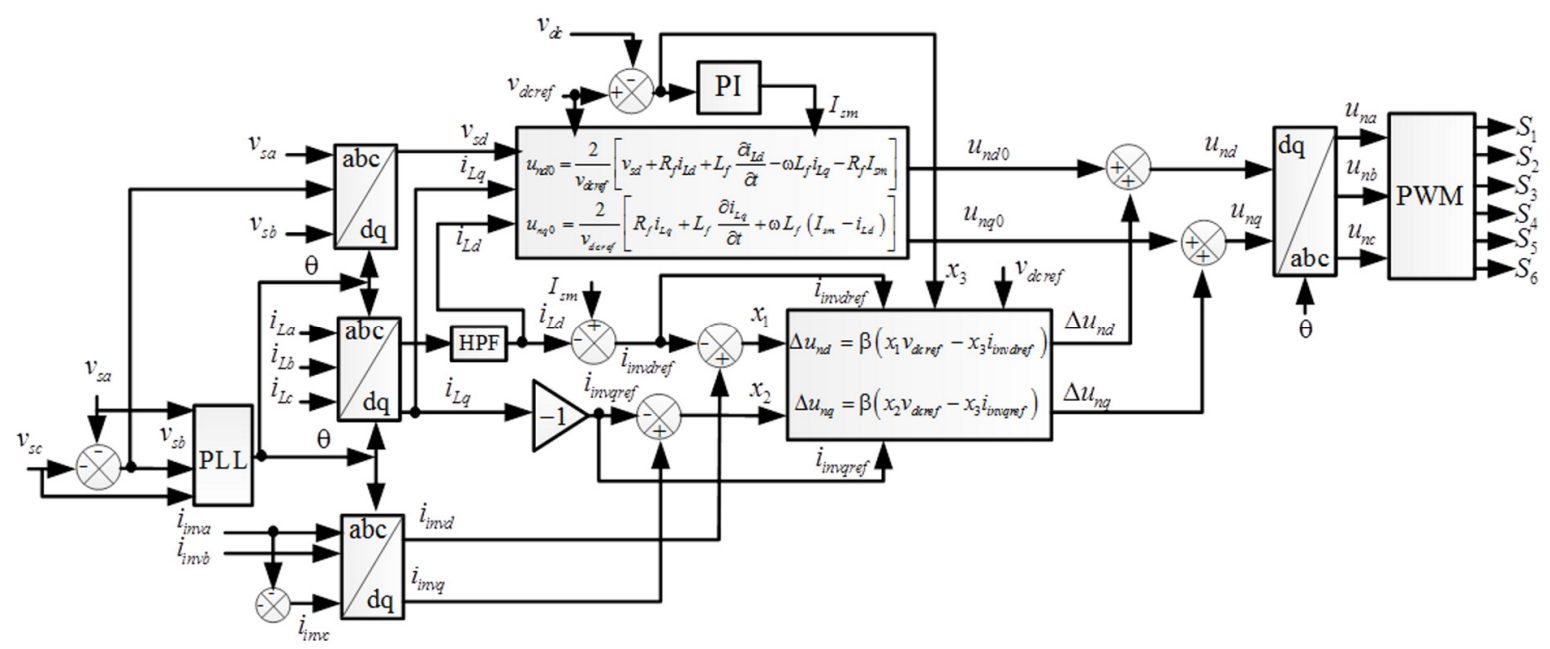

Fig. 5. Control algorithm of the DC-AC inverter.

system trajectories. The positive definite Lyapunov function in this case is described as follows,

$$
V=(3 / 2) L_{f} x_{1}^{2}+(3 / 2) L_{f} x_{2}^{2}+(1 / 2) C_{d c} x_{3}^{2}
$$

Thus, system is considered stable if the derivative of (31) is negative. 


$$
(\partial V / \partial t)=\left(\partial\left((3 / 2) L_{f} x_{1}^{2}+(3 / 2) L_{f} x_{2}^{2}+(1 / 2) C_{d c} x_{3}^{2}\right) / \partial t\right)<0
$$

Rearrangement of (32) gives,

$$
(\partial V / \partial t)=3 L_{f} x_{1}\left(\partial x_{1} / \partial t\right)+3 L_{f} x_{2}\left(\partial x_{2} / \partial t\right)+C_{d c} x_{3}\left(\partial x_{3} / \partial t\right)<0
$$

Considering,

$$
x_{1}=\left(i_{\text {invd }}-i_{\text {invdref }}\right), x_{2}=\left(i_{\text {ivvq }}-i_{\text {ivquref }}\right), x_{3}=\left(v_{d c}-v_{\text {dcref }}\right)
$$

Substituting (30) and (32) in (28), and with help of (29), the following expressions are obtained as,

$$
\begin{aligned}
& \left(\partial x_{1} / \partial t\right)=-\left(R_{f} / L_{f}\right) x_{1}+\omega x_{2}-\left(\left(u_{n d 0}+\Delta u_{n d}\right) / L_{f}\right) x_{3}+\left(v_{s d} / L_{f}\right) \\
& \left(\partial x_{2} / \partial t\right)=-\left(R_{f} / L_{f}\right) x_{2}-\omega x_{1}-\left(\left(u_{n q 0}+\Delta u_{n q}\right) / L_{f}\right) x_{3} \\
& \left(\partial x_{3} / \partial t\right)=(3 / 4)\left(\begin{array}{l}
\left(\left(u_{n d 0}+\Delta u_{n d}\right) / C_{d c}\right)\left(x_{1}+i_{n v d r e f}\right)+ \\
\left(\left(u_{n q 0}+\Delta u_{n q}\right) / C_{d c}\right)\left(x_{2}+i_{n v q r e f}\right)
\end{array}\right)
\end{aligned}
$$

Substituting (35), (36) and (37) in (34) gives the following expression,

$$
\begin{aligned}
(\partial V / \partial t) & =\overbrace{-3 R_{f}\left(x_{1}^{2}+x_{2}^{2}\right)-(3 / 2)\left(x_{1} v_{\text {dcref }}-x_{3} i_{\text {invdref }}\right) \Delta u_{n d}}^{\text {Term3 }} \\
& -\overbrace{(3 / 2)\left(x_{2} v_{\text {dcref }}-x_{3} i_{\text {invqref }}\right) \Delta u_{n q}}^{\text {Term } 2}
\end{aligned}
$$

It is observed that the first term $\overbrace{-3 R_{f}\left(x_{1}^{2}+x_{2}^{2}\right)}^{\text {Term } 1}$ is always negative. Therefore, to verify the Lyapunov stability condition, the second and the third terms should be negative. To obtain this negative sign, the perturbations of the global switching $\left(\Delta u_{n d}\right.$ and $\Delta u_{n q}$ ) should be chosen as follows,

$$
\begin{array}{ll}
\Delta u_{n d}=\beta\left(x_{1} v_{d c r e f}-x_{3} i_{\text {invdref }}\right), & \beta>0 \\
\Delta u_{n q}=\beta\left(x_{2} v_{d c r e f}-x_{3} i_{\text {invqref }}\right), & \beta>0
\end{array}
$$

where $\beta$ denote the gain of the controller.

\section{2) Choice of $\beta$}

The choice of $\beta$ is based on the dynamic response of the system and desired power quality at the PCC. However, the correct value of $\beta$ corresponds to fast dynamic response of system and less harmonic distortion (THD) of grid current at the PCC. In order to achieve these objectives, several cases with different $\beta$ are considered as given in Table I. It is observed that with $\beta=5$, the response of the system is fast ( $(=0.16 \mathrm{~s})$ and the THD grid current is least (3.4\%). Therefore $\beta$ is considered 5 for obtaining the control. 
TABLE I

CHOICE OF B

\begin{tabular}{c|c|c}
\hline \hline$\beta$ & Time response (s) & THD at the PCC (\%) \\
\hline 0.1 & 0.2 & 8.10 \\
\hline 0.5 & 0.165 & 4.16 \\
\hline 1 & 0.16 & 3.68 \\
\hline 2.5 & 0.16 & 3.5 \\
\hline 5 & 0.16 & 3.4 \\
\hline 10 & 0.16 & 6.72 \\
\hline 20 & 0.16 & 6.79 \\
\hline
\end{tabular}

\section{3) $D C$ Voltage regulation}

The DC-link voltage $\left(v_{d c}\right)$ must be maintained constant at the reference value to ensure correct injection of the power to the grid under change in solar irradiance and to improve the power quality at the PCC. As shown in Fig. 6, a conventional PI controller is adopted to regulate the DC-link voltage.

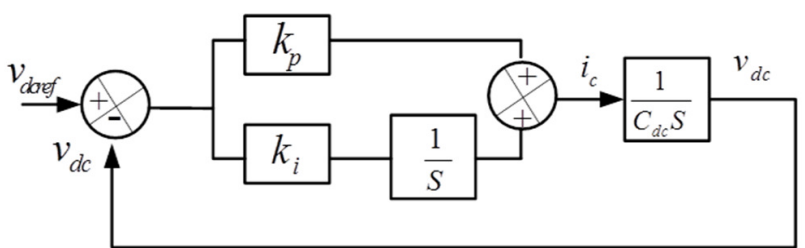

Fig. 6. Transfer function of the DC link voltage regulation.

The output of PI controller in the time domain is given as:

$$
i_{c}(t)=k_{p} \Delta v_{d c}(t)+k_{i} \int \Delta v_{d c}(t) d t
$$

where $k_{p}, k_{i}, i_{c}(\mathrm{t})$ and $\Delta v_{d c}(\mathrm{t})$ denote the proportional and integral coefficients, link active power component of grid current and the DC link voltage error.

The transfer function of a PI controller is found by taking the Laplace transform of equation given in (41) as:

$$
G(s)=k_{p}+\left(k_{i} / s\right)
$$

The open-loop transfer function of the DC link voltage regulation loop shown in Fig.6 is described as:

$$
G(s)=\left(k_{p}+\left(k_{i} / s\right)\right)\left(1 /\left(C_{d c} s\right)\right)
$$

And the corresponding closed-loop transfer function is expressed as:

$$
H(s)=\left(1 / C_{d c}\right)\left(\left(k_{p} s+k_{i}\right) /\left(s^{2}+\left(k_{p} / C_{d c}\right) s+\left(k_{i} / C_{d c}\right)\right)\right)(44)
$$

The closed-loop function $H(S)$ is second-order system, in which the damping ratios $\xi$ and the system bandwidth $\omega_{c}$ are equal to:

$$
\left\{\begin{array}{l}
2 \xi \omega_{c}=\left(k_{p} / C_{d c}\right) \Rightarrow k_{p}=2 C_{d c} \xi \omega_{c} \\
\omega_{c}^{2}=\left(k_{i} / C_{d c}\right) \Rightarrow k_{i}=C_{d c} \omega_{c}{ }^{2}
\end{array}\right.
$$

To achieve a good compromise between dynamic and static performances, the value of damping ratios $\xi$ must lie between 0.4 and 0.8. The bandwidth frequency that gives phase margin varies between $45^{\circ}$ to $65^{\circ}$. Bode plot based on different values of the bandwidth frequency is used as shown in Fig.7. It is observed that for fast and stable response, the bandwidth frequency is equal 
to $433 \mathrm{rad} / \mathrm{s}$ and the phase margin is equal to $64^{\circ}$. The $k_{p}$ and $k_{i}$ corresponding to the selected bandwidth frequency are 0.98 and 200 , respectively.

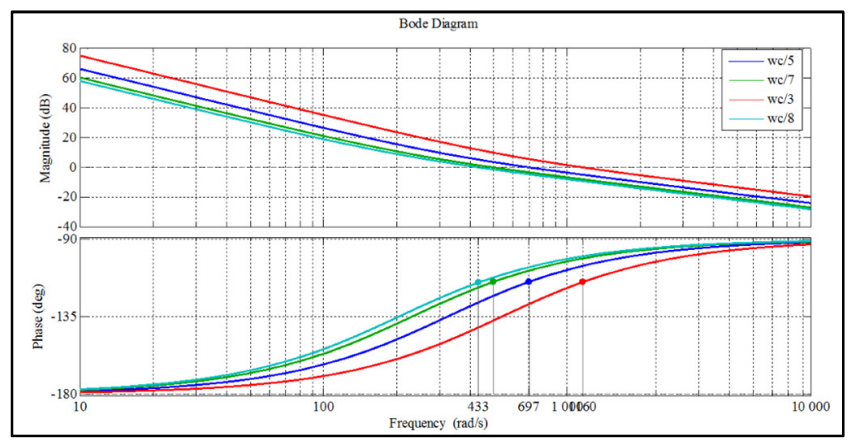

Fig. 7. Bode diagram for the open loop transfer function of the DC link voltage regulation.

\section{4) Selecting of DC-Link Voltage}

The minimum DC-link voltage of VSC should be greater than twice the peak of the AC phase voltage of the grid. The DC link voltage $\left(V_{d c}\right)$ is estimated as [31]:

$$
V_{d c} \geq v_{s a b}((2 \sqrt{2}) /(\sqrt{3} m))
$$

where, $V_{d c}, m$ and $v_{s a b}$ denote the minimum value of the DC link voltage, modulation index, which is considered as 1 , and the AC phase voltage of the grid, respectively. Hence, the minimum DC-link voltage from (42) is estimated as, $81.64 \mathrm{~V}$, and is selected as, $120 \mathrm{~V}$.

\section{SIMULATION AND EXPERIMENTAL RESULTS}

The performance of the solar-PV power generation system as shown in Fig.1 and its proposed control algorithm presented in Figs. 2 and 5, are verified using simulation model developed in MATLAB/Simulink. A prototype of the system is developed in the laboratory as shown in Fig.8. The performance is evaluated on a small scale 500 VA system using DSP (dSPACE) controller, LabVolt solar emulator is used as a PV array. Hall's Effect current sensors (LEM LA-55P), Hall's Effect voltage sensors (LEM LV-25P), signal conditioning circuit, three-leg ready on shelf inverter and DC-DC boost converter are used for prototype development. The gating signals for converters are obtained using three-phase and single-phase PWM blocks of DSP and an isolation card.

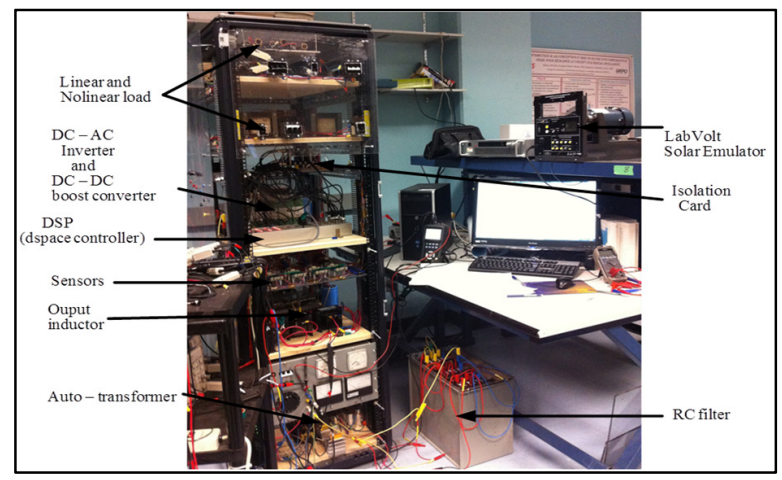

Fig. 8. Photograph of Experimental System.

\section{A. Performance under Change in Solar Irradiation}

Fig. 9 shows simulated results obtained in terms of grid volatge $\left(v_{s}\right)$, grid currents $\left(i_{s}\right)$, load currents $\left(i_{L}\right)$, inverter currents $\left(i_{\text {inv }}\right)$, PV current $\left(i_{p v r e f}\right.$ and $\left.i_{p v}\right)$, DC voltage $\left(\mathrm{v}_{\mathrm{dcref}}\right.$ and $\left.\mathrm{v}_{\mathrm{dc}}\right)$, grid power $\left(\mathrm{P}_{\mathrm{s}}\right)$, load power $\left(\mathrm{P}_{\mathrm{L}}\right)$ and inverter power $\left(\mathrm{P}_{\text {inv }}\right)$. The load demand is negligible under the case. 


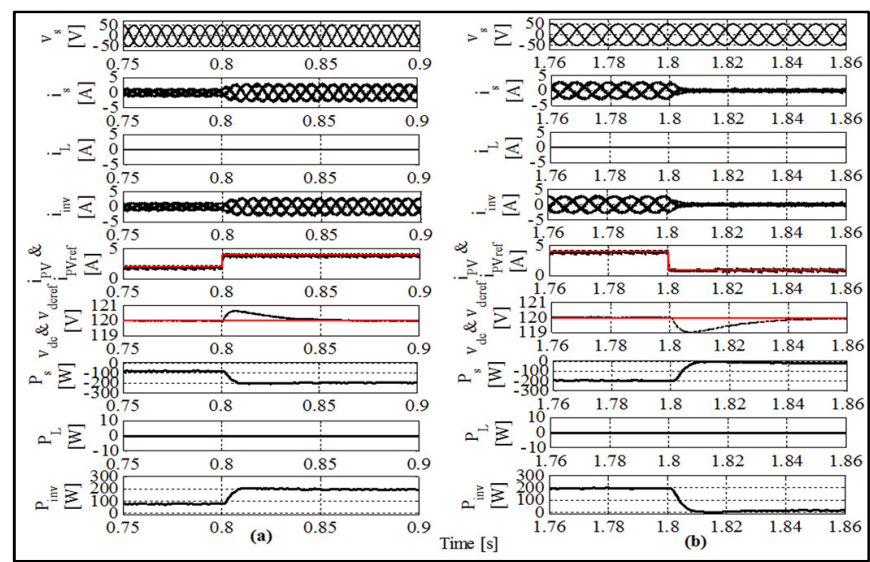

Fig. 9. Dynamic response of the DC/AC inverter under: a) increasing load and solar irradiation, and b) decreasing load and solar irradiation.

It is observed in Fig.9 (a) that at $0.8 \mathrm{~s}$, solar irradiation is increased and it results in an increase in $i_{p v}$ and $i_{s}$. The DC bus voltage is well regulated. Due to absence of any load demand, the power provided by PV array is equal to that injected to the grid. In Fig.9 (b), the system is subjected to sudden decrease of the solar irradiation at $1.8 \mathrm{~s}$, and it is observed that $i_{p v}$ and $i_{s}$ are decreased. It is noted that even under reduction in solar-PV power, the DC voltage is well regulated and the steady state error is negligible and the PV current follows its reference. It confirms the robustness of the control algorithms used for DC-DC boost converter and DC-AC inverter in steady state and dynamic conditions.

\section{B. Performance under Change in Nonlinear Loads}

Fig.10 shows simulation results under load perturbations at constant solar irradiation. Three-phase diode bridge rectifier feeding resistive-inductive load is considered as nonlinear load. Three-phase loads are unbalanced between $0.8 \mathrm{~s}$ and $1.8 \mathrm{~s}$. It is observed in Fig.10 (a) that until 0.78 s balanced nonlinear load is connected at the PCC and at $0.8 \mathrm{~s}$, the load on phase 'b' is switched off. The grid currents are perfectly balanced and sinusoidal. The inverter serves the functions of load balancer and harmonics compensator and injects the active power generated by PV array in to the grid. In Fig.10 (b) simulation results during switching in load of phase ' $b$ ' again at $1.8 \mathrm{~s}$ are presented. It is observed that the active power injected in to grid is decreased after $1.8 \mathrm{~s}$ due to an increase in load demand.

Fig. 11 shows the control laws $\left(u_{n d}\right)$ and $\left(u_{n q}\right)$, which are obtained using experimental test (a), and that obtained using simulation under identical operating conditions (b).

It is observed that the obtained simulation and experimental results are same, confirming the validation of the proposed control approach for the DC-AC inverter.

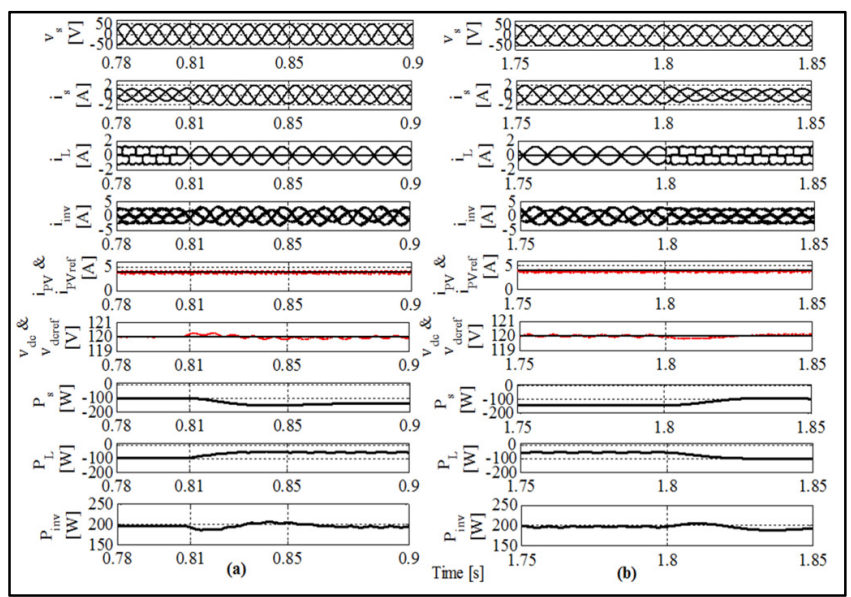

Fig. 10.Dynamic response of the DC/AC inverter under nonlinear loads (a) fixed solar irradiation and switching off load on phase 'a' at $t=0.81 \mathrm{~s}$ (b) fixed solar irradiation and switching on load on phase 'a' at $\mathrm{t}=1.8 \mathrm{~s}$. 


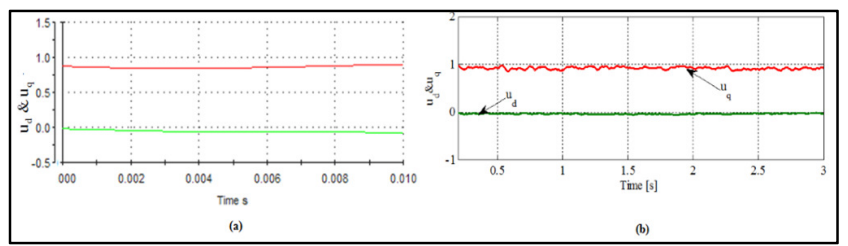

Fig. 11. $u_{n d}$ and $u_{n q}$ obtained at: a) experimental result and b) simulation result.

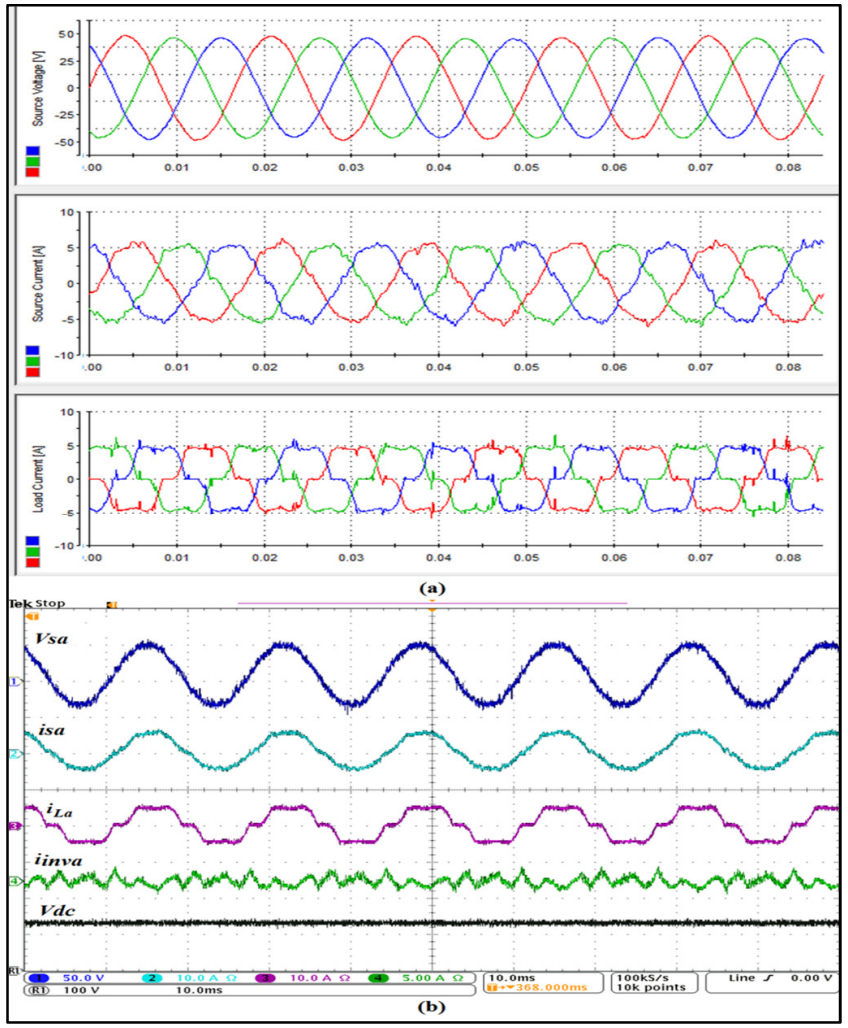

Fig. 12. (a) Three-phases real-time steady-state snapshot at grid side in the presence of balanced nonlinear loads (b) Oscilloscope results of one phase.

Fig.12 (a) shows the real-time steady-state snapshots of response obtained in terms of three-phase grid voltages ( $\left.v_{s a b c}\right)$, grid currents $\left(i_{s a b c}\right)$, and load currents $\left(i_{L a b c}\right)$. In Fig.12 (b), the results are obtained for a typical phase 'a' variables and DC link voltage. It is observed that even in presence of balanced nonlinear loads, the grid voltages and currents are balanced and sinusoidal. To achieve faster convergence and an improved THD, the constant $\beta$ is selected equal to 5. However, smaller $\beta$ values can contribute to improve the steady-state performance but they affect the dynamic response of the developed controller.

Figs.13 (a) and (b) present experimental results in terms of grid voltage $\left(v_{s a}\right)$, grid current $\left(i_{s a}\right)$, DC link voltage $\left(v_{d c}\right)$ and inverter current $\left(i_{\text {inva }}\right)$ under rise and fall of solar irradiations at fixed nonlinear loads. It is observed in Fig.13 (a) that when solar irradiation is increased at $\mathrm{t}=0.2 \mathrm{~s}$, grid current is increased and is in out of phase with grid voltage, which leads that PV array is injecting power to the grid. However, in Fig. 13 (b) when solar irradiation decreases at $t=0.2 \mathrm{~s}$, grid current becomes in phase with grid voltage. In this case, grid is supplying deficit load demands.

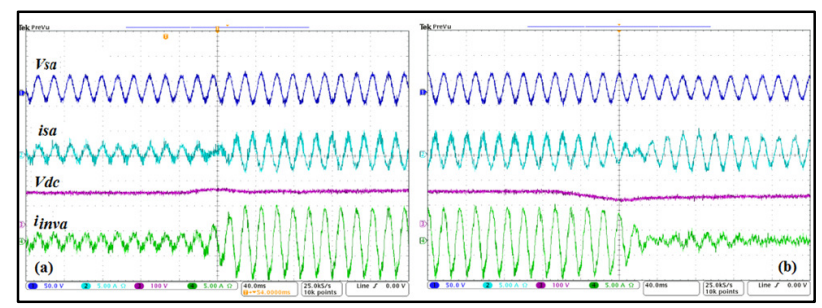

Fig. 13. Dynamic response of the DC/AC inverter under (a) sudden increasing of solar irradiation, and (b) sudden decreasing of solar irradiation at fixed nonlinear load. 
Fig14 shows the real-time snapshots of response in terms of three-phase grid voltages $\left(v_{s a b c}\right)$, grid currents $\left(i_{s a b c}\right)$, and load currents $\left(i_{L a b c}\right)$ in the presence of unbalanced and balanced nonlinear loads during absence of the solar irradiation. It is observed that the grid currents and voltages are completely balanced and sinusoidal, which confirms the robustness of the proposed approach based on Lyapunov function for power quality improvement at the PCC.

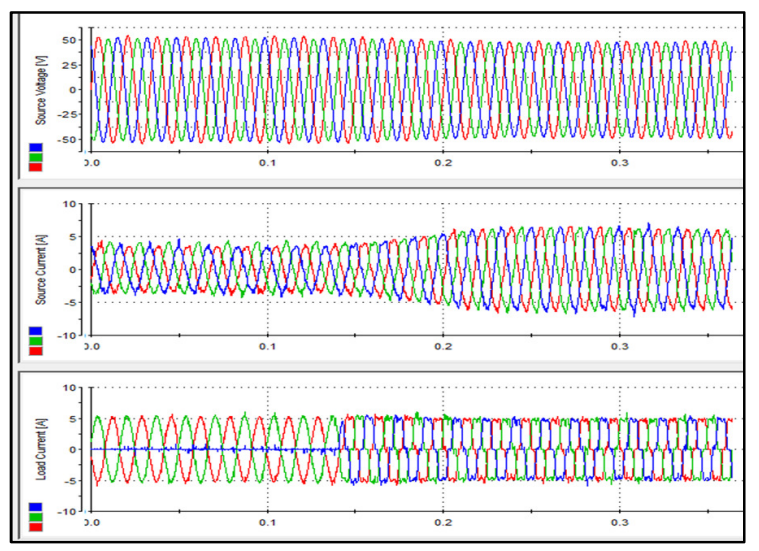

Fig. 14. Three phases real-time steady-state response of the DC/AC inverter in the presence of unbalanced nonlinear loads and absence of solar irradiation.

Figs. 15(a-b) show zoomed view of test results recorded under balanced/ unbalanced nonlinear load with constant solar irradiation. It is found that the system is stable and the DC-AC inverter behaves as a shunt active filter. It compensates load current harmonics and provides balanced grid currents under unbalanced nonlinear loads. In addition, the DC voltage is also regulated at its reference value.

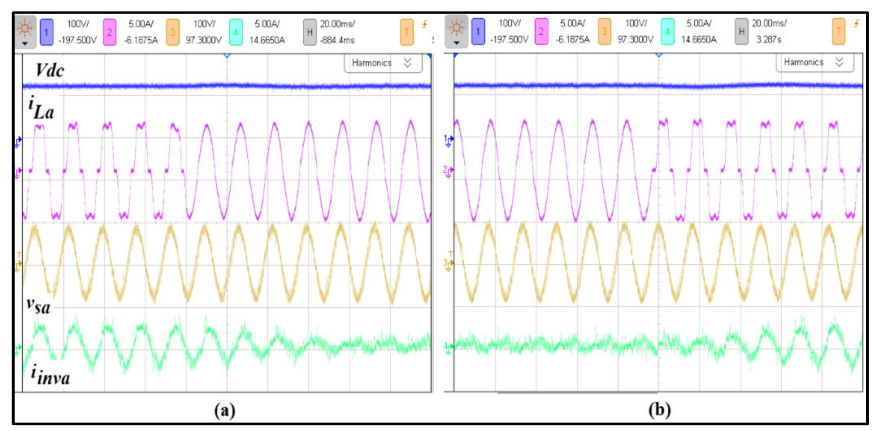

Fig. 15. Test results of the DC voltage, load current, grid voltage and inverter current in the presence of balanced and unbalanced nonlinear load and at fixed solar irradiation.

Fig.16 (a) shows test results in terms of $v_{d c}, i_{p v}, v_{s a}$, and $i_{s a}$ during increasing in solar irradiation under no load conditions. Fig.16 (b) shows results during decreasing in solar irradiation under similar conditions. In Fig.16(c), it shows zoomed waveforms. It is found that the PV current changes under variation of the solar irradiation and subsequent changes are noticed in grid current. It employs the robustness of the proposed control for the DC-DC boost converter. It is clear that the dynamic response in terms of regulation the DC voltage is fast during the transient period (increasing and decreasing of the solar irradiation). 


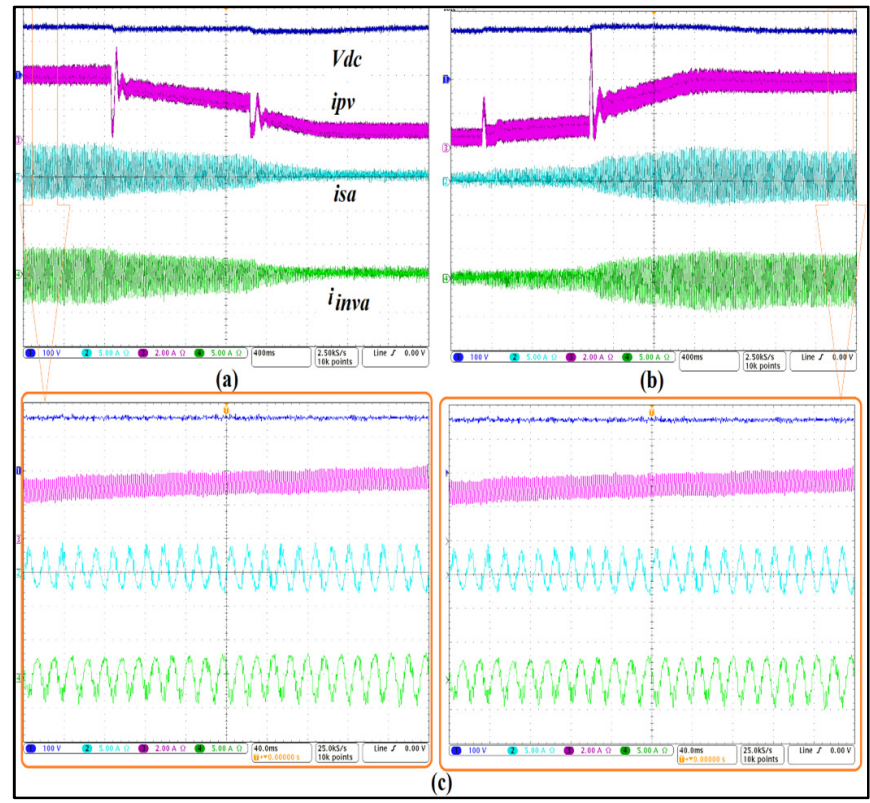

Fig. 16. Experimental results of the DC voltage, output PV current, grid current, and inverter current during solar irradiation change at no load.

Figs.17 (a-c) present harmonic spectra and THDs of the load current, grid current and grid voltage for phase 'a', respectively. These THDs of grid current and voltage are within acceptable standard limits of 5\% when the load current THD is $18.2 \%$. It clearly demonstrates that proposed control algorithm serves the function of harmonics eliminator.

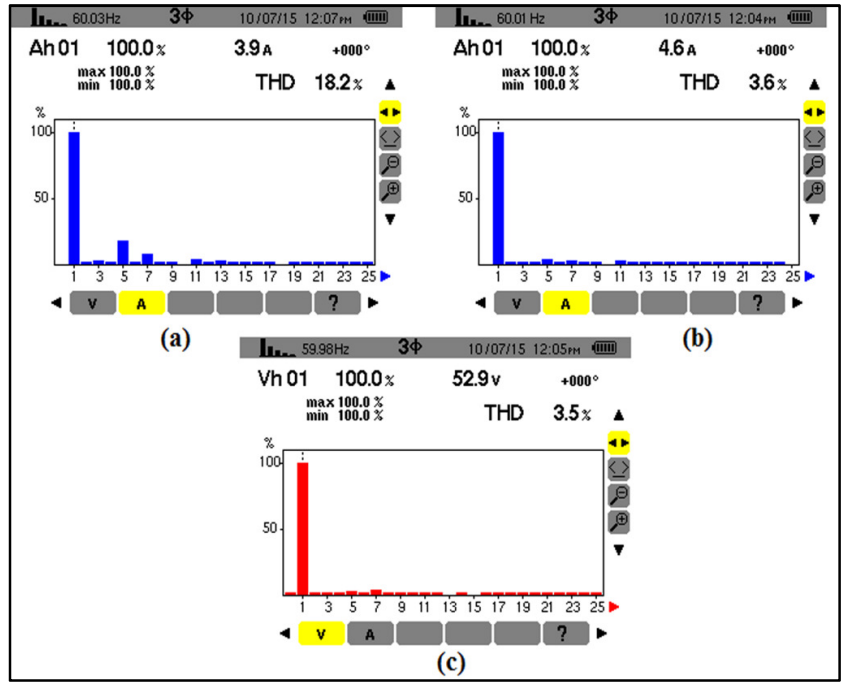

Fig. 17. Harmonics spectra of (a) load current, (b) grid current, and (c) grid voltage.

\section{CONCLUSION}

A sliding mode and Lyapunov function based control algorithms have been presented for the boost converter and DC-AC inverter used for solar-PV power generating system array tied with the grid. Detailed design and stability analysis for both control approaches have been discussed to confirm its applicability under various operating conditions. The proposed approach has minimized the requirements of PI controller and only single PI controller is employed for DC bus voltage loop. The obtained simulation and experimental results have established that presented control approach performs satisfactorily under different operating conditions without adjusting the controller parameters. 


\begin{tabular}{llll}
\multicolumn{5}{c}{$\begin{array}{c}\text { APPENDIX } \\
\text { TABLE II }\end{array}$} \\
\multicolumn{1}{c}{ SYSTEM FOR MAGNETIC PARAMETERS } \\
\hline \hline Parameters & \multicolumn{1}{c}{ Value } & Parameters & Value \\
\hline$i_{r r}$ & $5.981 .10^{-8} \mathrm{~A}$ & $f_{s w}$ & $10 \mathrm{kHz}$ \\
$i_{\text {scr }}$ & $3.81 \mathrm{~A}$ & $L_{f}$ & $5 \mathrm{mH}$ \\
$k_{i}$ & 0.0024 & $R_{f}$ & $0.025 \Omega$ \\
$T_{r}$ & $298 \mathrm{~K}$ & $k$ & 50 \\
$q$ & $1.6 .10^{-19} \mathrm{C}$ & $\beta$ & 5 \\
$k_{b}$ & $1.38 .10^{-23} \mathrm{~J} / \mathrm{K}$ & $k_{p}$ & 0.98 \\
$E_{g}$ & $1.12 \mathrm{~V}$ & $k_{i}$ & 200 \\
$A$ & 1.2 & $C_{p v}$ & $100 \mu \mathrm{F}$ \\
$L$ & $1.5 \mathrm{mH}$ & $f$ & $60 \mathrm{~Hz}$ \\
$C_{\text {out }}$ & $200 \mu \mathrm{F}$ & $v_{L m a x}$ & $50 \mathrm{~V}$ \\
$R_{c}$ & $2.5 \Omega$ & $v_{d c}$ & $120 \mathrm{~V}$ \\
$C_{c}$ & $10 \mu \mathrm{F}$ & $C_{d c}$ & $2500 \mu \mathrm{F}$ \\
\hline \hline
\end{tabular}

\section{REFERENCES}

[1] W. Fengjiang, S. Bo, D. Jiandong, and Z. Ke, “Online Variable Topology-Type Photovoltaic Grid-Connected Inverter,” IEEE Trans. Ind. Electron, vol. 62, no.4, pp. 4814-4822, Aug. 2015.

[2] IEEE, "IEEE Recommended Practice for Establishing Methods and Procedures that Provide Supplemental Support for Implementation Strategies," in IEEE Std 1547-2014, ed, 2014, pp.1-176.

[3] H.M. Hasanien, "An Adaptive Control Strategy for Low Voltage Ride Through Capability Enhancement of Grid-Connected Photovoltaic Power Plants," IEEE Trans. Power Systems, vol. 31, no.4, pp. 3230-3237, July 2016.

[4] S. Jain and V. Agarwal, "A Single-Stage Grid Connected Inverter Topology for Solar PV Systems With Maximum Power Point Tracking," IEEE Trans. Power Electron, vol. 22, no.5, pp. 1928-1940, Sept. 2007.

[5] C. Meza, D. Biel, D. Jeltsema, and J. M. A. Scherpen, "Lyapunov-Based Control Scheme for Single-Phase Grid-Connected PV Central Inverters," IEEE Trans. Control Systems Technology, vol. 20, no.2, pp. 520-529, March 2012.

[6] S. A. Arshadi, B. Poorali, E. Adib, and H. Farzanehfard, "High Step-Up DC-AC Inverter Suitable for AC Module Applications," IEEE Trans.Ind. Electron, vol. 63, no.2, pp. 832-839, Feb. 2016.

[7] M. Mirhosseini, J. Pou, and V. G. Agelidis, "Single- and Two-Stage Inverter-Based Grid-Connected Photovoltaic Power Plants With Ride-Through Capability Under Grid Faults, ” IEEE Trans. Sustainable Energy, vol. 6, no.3, pp. 1150-1159, July 2015.

[8] M. Rezkallah, A. Hamadi, A. Chandra, and B. Singh, "Real-Time HIL Implementation of Sliding Mode Control for Standalone System Based on PV Array Without Using Dumpload, "IEEE Trans. Sustainable Energy, vol. 6, no.4, pp. 1389-1398, Oct. 2015.

[9] Y. Zhu, J. Yao, and D. Wu, "Comparative study of two stages and single stage topologies for grid-tie photovoltaic generation by PSCAD/EMTDC, " in Proc. Advanced Power System Automation and Protection (APAP), Beijing, China, 2011, pp. 1304-1309.

[10] B. Subudhi and R. Pradhan, "A Comparative Study on Maximum Power Point Tracking Techniques for Photovoltaic Power Systems," IEEE Trans. Sustainable Energy, vol. 4, no.1, pp. 89-98, Jan. 2013.

[11] N. Femia, G. Petrone, G. Spagnuolo, and M. Vitelli, “Optimization of perturb and observe maximum power point tracking method, "IEEE Trans. Power Electron, vol. 20, no.4, pp. 963-973, July 2005.

[12] D. Shmilovitz, "On the control of photovoltaic maximum power point tracker via output parameters," IET Electric Power Applications, vol. 152, no. 2, pp. 239-248, March 2005.

[13] Y. Jiang, J. A. A. Qahouq, and T. A. Haskew, “Adaptive Step Size With Adaptive-Perturbation-Frequency Digital MPPT Controller for a Single-Sensor Photovoltaic Solar System," IEEE Trans. Power Electron, vol. 28, no. 2, pp. 3195-3205, July 2013.

[14] J. J. Mor, P. F. Puleston, C. Kunusch, and M. A. Fantova, "Development and Implementation of a Supervisor Strategy and Sliding Mode Control Setup for Fuel-Cell-Based Hybrid Generation Systems," IEEE Trans. Energy Conversion, vol. 30, no.1, pp. 218-225, March 2015.

[15] M. Edardar, X. Tan, and H. K. Khalil, "Design and Analysis of Sliding Mode Controller Under Approximate Hysteresis Compensation," IEEE Trans. Control Systems Technology, vol. 23, no.2, pp. 598-608, March 2015.

[16] C. Min-Shin, H. Yean-Ren, and M. Tomizuka, "A state-dependent boundary layer design for sliding mode control," IEEE Trans. Automatic Control, vol. 47, no.10, pp. 1677-1681, Oct. 2002.

[17] A. Ferreira, F. J. Bejarano, and L. M. Fridman, "Robust Control With Exact Uncertainties Compensation: With or Without Chattering?" IEEE Trans. Control Systems Technology, vol. 19, no.5, pp. 969-975, Sept. 2011.

[18] P. Liutanakul, S. Pierfederici, and F. Meibody-Tabar, "Application of SMC With I/O Feedback Linearization to the Control of the Cascade ControlledRectifier/Inverter-Motor Drive System With Small dc-Link Capacitor," IEEE Trans. Power Electronic, vol. 23, no.5, pp. 2489-2499, Sept. 2008.

[19] C. C. Chen, S. S. D. Xu, and Y. W. Liang, "Study of Nonlinear Integral Sliding Mode Fault-Tolerant Control," IEEE Trans. Mechatronics, vol. 21, no.2, pp. 1160-1168, April 2016.

[20] Q. Xu, "Digital Integral Terminal Sliding Mode Predictive Control of Piezoelectric-Driven Motion System," IEEE Trans. Ind. Electron, vol. 63, no.6, pp. 3976-3984, June 2016.

[21] A. M. Shotorbani, A. Ajami, S. G. Zadeh, M. P. Aghababa, and B. Mahboubi, "Robust terminal sliding mode power flow controller using unified power flow controller with adaptive observer and local measurement," IET Generation, Transmission and Distribution, vol. 8, no. 10, pp. $1712-1723$, Oct. 2014.

[22] R. J. Wai, Y. F. Lin, and Y. K. Liu, "Design of Adaptive Fuzzy-Neural-Network Control for a Single-Stage Boost Inverter," IEEE Trans. Power Electron, vol. 30, pp. 7282-7298, Dec. 2015

[23] H. Komurcugil, “Adaptive terminal sliding-mode control strategy for DC-DC buck converters," ISA Transactions, vol. 51, no. 6, pp. 673-81, Nov. 2012.

[24] S. C. Tan, Y. M. Lai, and C. K. Tse, "General Design Issues of Sliding-Mode Controllers in DC-DC Converters," IEEE Trans. Ind. Electron, vol. 55, no. 3, pp. 1160-1174, March 2008

[25] D. G. Montoya, C. A. Ramos-Paja, and R. Giral, "Improved Design of Sliding-Mode Controllers Based on the Requirements of MPPT Techniques," IEEE Trans. Power Electron, vol. 31, no.1, pp. 235-247, Jan. 2016.

[26] M. P. Akter, S. Mekhilef, N. M. L. Tan, and H. Akagi, "Modified Model Predictive Control of a Bidirectional AC-DC Converter Based on Lyapunov Function for Energy Storage Systems," IEEE Trans. Ind. Electron, vol. 63, no.2, pp. 704-715, Feb.2016.

[27] S. Adhikari, F. Li, and H. Li, "P-Q and P-V Control of Photovoltaic Generators in Distribution Systems," IEEE Trans. Smart Grid, vol. 6, no.6, pp. 29292941, Nov. 2015. 
[28] J. W. Jung, N. T. T. Vu, D. Q. Dang, T. D. Do, Y. S. Choi, and H. H. Choi, "A Three-Phase Inverter for a Standalone Distributed Generation System: Adaptive Voltage Control Design and Stability Analysis,” IEEE Trans. Energy Conversion, vol. 29, no.1, pp. 46-56, March 2014.

[29] S. Rahmani, A. Hamadi, and K. Al-Haddad, "A Lyapunov-Function-Based Control for a Three-Phase Shunt Hybrid Active Filter," IEEE Trans. Ind. Electron, vol. 59, no.3, pp. 1418-1429, March 2012.

[30] H. Komurcugil, N. Altin, S. Ozdemir, and I. Sefa, “An Extended Lyapunov-Function-Based Control Strategy for Single-Phase UPS Inverters," IEEE Trans. Power Electron, vol. 30, , no.7, pp. 3976-3983, July 2015.

[31] B. Singh, A. Chandra, and K. Al-Haddad, Power Quality Problems And Mitigation Techniques, 1st ed, Chichester, West Sussex, United Kingdom, John Wiley\& Sons Ltd, 2015, pp.132-133.

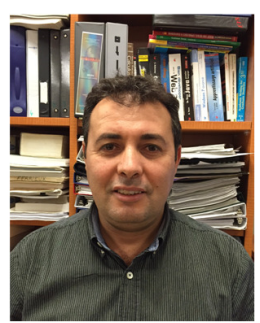

Miloud Rezkallah (S'11-M'14) received the B. Tech. degree in electrical machines and drive from the University of Science and Technology USTO (now University Mohamed Boudiaf), Oran, Algeria, and the M. Tech. and Ph.D. degrees in power electronics and system control from École de Technologie Supérieure, Université du Québec, Montréal, Canada., in 2010 and 2016, respectively. He is working as a post-doctoral research fellow in Electrical Engineering Department at École de Technologie Supérieure. His research interests include control and design of microgrid, active filters, renewable energy generations and applications, and energy storage systems.

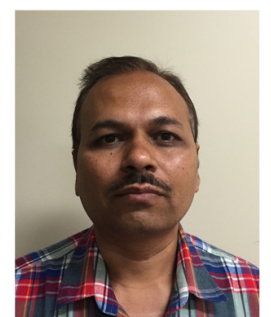

Shailendra Kumar Sharma ( SM'2009, M' 2012, SM' 2015) did his M. E. degree from Shri G. S. Institute of Technology \& Science Indore and Ph.D. degree from Indian Institute of Technology Delhi, in 2004 and 2012 respectively. He worked as an Erection and Commissioning Engineer in Textile and Power Industries during 19952002. Since 2004, He is working as an Assistant Professor in Electrical Engineering Department at Shri G. S. Institute of Technology \& Science Indore, Madhya Pradesh India. He was post-doctoral research fellow during 2015-16 in Electrical Engineering Department at École de Technologie Supérieure (ÉTS), Université du Québec , Montréal, Canada. His main research interests are control of stand-alone non-conventional energy sources, distributed energy resources with grid, power quality and special machine drives. Dr. Sharma is a senior member IEEE and Associate Member of Institution of Engineers (India) (AMIE).

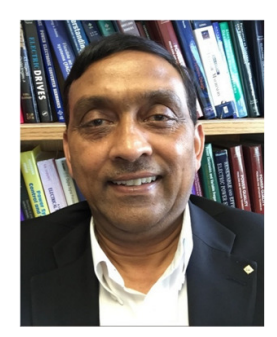

Ambrish Chandra (SM'99-F'14) received the Electrical engineering degree from Indian Institute of Technology (IIT), Roorkee, India, in 1977 the M.Tech. degree in power apparatus and systems from the IIT, in1980, and the Ph.D. degree from the University of Calgary, Canada, in 1987. From 2012 to 2015, he was the Director of the graduate program on "renewable energy and energy efficiency" at the Ecole de Technologie Supérieure (ETS), Université du Québec, Montréal, QC, Canada, where since 1994, he has been a Professor with the Department of Electrical Engineering. His research interests include power quality, active filters, static reactive power compensation, flexible ac transmission systems (FACTS), and control and integration of renewable energy resources. He has coauthored the book Power Quality_Problems and Mitigation Techniques (Wiley, 2015). He is a Distinguished Lecturer of IEEE Power and Energy Society and also of IEEE Industry Application Society. Dr. Chandra is an Associate Editor of the IEEE Transactions on Industrial Electronics. He is a Professional Engineer in the Province of Quebec, Canada.

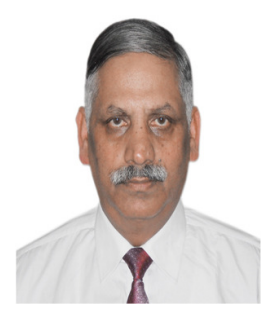

Bhim Singh (SM'99, F'10) was born in Rahamapur, Bijnor (UP), India, in 1956. He received his B.E. (Electrical) from the University of Roorkee, India, in 1977 and his M.Tech. and Ph.D. from the IIT Delhi, India, in 1979 and 1983, respectively. In 1983, he joined the Department of Electrical Engineering, University of Roorkee as a Lecturer. He became a Reader there in 1988. In December 1990, he joined the Department of Electrical Engineering, IIT Delhi, India, as an Assistant Professor, where he has become a Professor in 1997. Presently he is Head of the Department of Electrical Engineering at IIT Delhi. Prof. Singh has guided 60 Ph.D. dissertations, 161 M.E./M.Tech./M.S.(R) theses. His areas of research interest include power electronics, electrical machines and drives, renewable energy, active filters, FACTS, HVDC, and power quality.

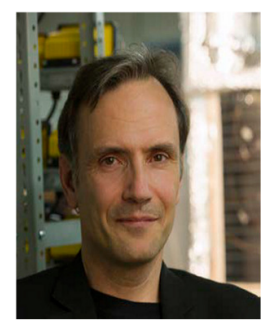

Daniel Rousse is a full professor at École de Technologie Supérieure (ÉTS), where he is director of t3e Group and director of the Masters in renewable energy and energy efficiency. He has studied philosophy and literature before completing an engineering degree and a Masters in Mechanical Engineering from École Polytechnique and a Ph.D. in mechanical engineering from McGill University (1994). Daniel Rousse was professor of energy at Laval University (1995) before accepting the position of Vice President for Development - Lévis campus at Université du Québec in Rimouski (2004) to build an energy efficient $15000 \mathrm{~m} 2$ campus involving a geothermal field of 125 boreholes, an enthalpy wheel, passive solar shields, active solar walls, etc. From 2007 to 2009 he was director of development and special projects of the network of the University du Quebec, in charge of the Energy Workshop involving four universities. Prof. His technologies research activities in energy and energy efficiency are focused on three main areas: solar, storage and sustainable buildings. 